\title{
METAPHORICAL EXTENSION AND THE EVOLUTION OF CONFIGURATIONALITY
}

\author{
T. Mark Ellison ${ }^{* 1}$ and Uta Reinöhl ${ }^{2}$ \\ *Corresponding Author: m.ellison@anu.edu.au \\ ${ }^{1}$ Wellsprings/CoEDL, Australian National University, Canberra, Australia \\ ${ }^{2}$ Institut für Linguistik, Universität zu Köln, Köln, Germany
}

Syntactic systems fall along a spectrum of configurationality. At one end, less-configurational languages arrange their sentences by information structure while at the more-configurational other end, word order is constrained by syntactic rules and requires the overt expression of specific words (e.g. adpositions requiring overt nominal arguments). Historical records show that some more-configurational languages, like English or Hindi, have developed from less-configurational (or non-configurational in the strict Australianist sense, Hale 1983) ancestral languages (Luraghi 2010, Reinöhl 2016). We present a computational model of the development of certain aspects of configurationality, drawing on work by Reinöhl (2016).

In studying the development of adpositions from nominals, Reinöhl (2016) discovered that metaphorical extension of relational terms leads to overt dependents becoming obligatory. Here, metaphorical means any usage where the relational term is combined with a semantically incompatible argument - incompatible under literal interpretation. For instance, the literal meaning of the relational term middle is only coherent with arguments that contain an actual, semantically retrievable centre (= roughly equidistant from the container's spatial and/or temporal boundaries) as in in the middle of the room or in the middle of the day. Besides this literal usage, middle can be used metaphorically when there is no well-defined centre. In the example A moment ago everything was OK. Suddenly, we are in the middle of a crisis, the word middle does not refer to the temporal centre of the crisis, in equidistance from its edges: the crisis may last for a week, but within 5 minutes we are in its middle.

When a relational term is used in a non-literal, metaphorical way as just illustrated, the target domain (e.g. the crisis) shows a strong bias for being overtly encoded in the same clause. In contrast, literal usages of middle need not specify a possessor, so long as it is already primed, as in The players arrived at the soccer field, the referee already standing in the middle. A British National Corpus (BNC) search of relevant constructions involving middle shows a bal- 
anced mix of possessed and unpossessed forms with literal interpretations, but only exceptional unpossessed forms where the interpretation is metaphorical.

Historical evidence from three millennia of Indo-Aryan history, stretching from Vedic Sanskrit to modern Hindi, shows the same phenomenon. In stage one (see ex. 1a), the Vedic Sanskrit noun मध्ये madhye in the locative case, meaning 'in the middle', is used in a basic spatial sense, i.e. referring to the middle point in spatial (or sometimes temporal) entities with an inherent centre, such as convex objects.

In the second stage (see ex. 1b), around two millennia later, madhye (now as majjhe/-i) occurs more often metaphorically, i.e. with entities that do not have inherent centres, and may not even be spatial or temporal. In these metaphorical usages, the possessor argument is always overt. In stage three (see ex. 1c), increasing metaphorical use over time leads to syntactic fixation of this construction. Madhye (as modern Hindi mẽ) has become semantically bleached, denoting simple containment (translatable as 'in'), and requires an explicit nominal dependent in all cases. This transition from a spatial noun to an adposition mirrors developments in numerous languages (Svorou 1988). The Indo-Aryan case study unveils how the dependents of adpositions may become obligatory due to incremental, semantically driven change.

\begin{tabular}{|l|l|l|}
\hline 1a) Vedic / literal use & 1b) Apabhramśa / metaphor & 1c) Hindi / semantic shift \\
\hline ... atha madhya ăghärayati ... & $\ldots$ majjhi mahattarāna ... & vah pareśānī me hai \\
\hline ... now middle pour.3sg ... & $\ldots$ middle of-best-ones ... & 3sg trouble.obl.sg.f in be.3sg \\
\hline $\begin{array}{l}\text { now he pours (ghee) onto the } \\
\text { middle (of the altar - omitted) }\end{array}$ & $\begin{array}{l}\text { in the middle of (i.e. among) } \\
\text { the best ones }\end{array}$ & s/he is in trouble \\
\hline
\end{tabular}

Hough et al. (2015) defines a set of desiderata for incremental dialogue systems, both as models of human cognitive processing and for natural language processing. One desireable feature is monotonicity: that all inferences true from the discourse before an input word is processed should still hold after it is processed. The processing of metaphors monotonically, however, leads to inconsistent representations, and thus wrong interpretations, unless the inconsistency is resolved by processing the metaphor - including a domain specifier - as a unit before integrating the new knowledge into the discourse representation. If metaphorical uses become sufficiently frequent, learners may infer that the argument is obligatory, while at the same time generalising the semantic sense of the term so that once metaphorical senses now become literal. We present simulations of obligatorification created by implementing one possible model of monotonic, incremental semantic parsing.

In summary, this poster describes how the process of metaphorical extension can lead to the obligatorification of arguments. 


\section{References}

Hale, K. (1983). Warlpiri and the grammar of non-configurational languages. Natural Language \& Linguistic Theory, 1(1), 5-47.

Hough, J., Kennington, C., Schlangen, D., \& Ginzburg, J. (2015). Incremental Semantics for Dialogue Processing: Requirements and a Comparison of Two Approaches. In Proceedings of the 11th International Conference on Computational Semantics (IWCS) 2015.

Luraghi, S. (2010). The rise (and possible downfall) of configurationality. In S. Luraghi \& V. Bubenik (Eds.), The continuum companion to historical linguistics (p. 212-229). London/New York: Continuum.

Reinöhl, U. (2016). Grammaticalization and the Rise of Configurationality in Indo-Aryan. Oxford: Oxford University Press.

Svorou, S. (1988). The experiential basis of the grammar of space. evidence from the languages of the world. (Unpublished doctoral dissertation). SUNY. 